\title{
Similaridades e diferenças entre o Mestrado Acadêmico e o Mestrado Profissional enquanto política pública de formação no campo da Saúde Pública
}

\author{
Similarities and diferences between Academic and Professional \\ Master Programs as Educational Public Policy in the field \\ of Public Health
}

Gideon Borges dos Santos ${ }^{1}$

Virginia Alonso Hortale ${ }^{1}$

Katia Mendes de Souza ${ }^{2}$

Anya Pimentel Gomes Fernandes Vieira-Meyer ${ }^{3}$

${ }^{1}$ Escola Nacional de Saúde Pública, Fiocruz. R. Leopoldo Bulhões 1480, Manguinhos. 21041-210 Rio de Janeiro RJ Brasil. gidborges@ensp.fiocruz.br ${ }^{2}$ Secretaria Municipal de Saúde de Petrópolis. Petrópolis RJ Brasil.

${ }^{3}$ Fundação Oswaldo Cruz Escritório Ceará. Fortaleza CE Brasil.

\begin{abstract}
In the attempt to find a specificity for the Professional Master Program in Public Health (PM), we asked, what is, from the point of view of its means and purposes, kept or broke from the training models of the Academic (traditional) Masters Program (AM). In the public health field, this discussion possess an extra "flavor", as both program aim, in Brazil, to prepare health professionals to the Brazilian Unified Health System (SUS). Therefore, this research sought to investigate the heuristic and innovative vocation of the PM vis-à-vis the AM as an education public policy. From a comparative approach, we analyzed the main characteristics and differences among AM and PM, face the flexibilization process of graduate programs in Brazil, and discussed if these features would characterize the PM into an educational public policy. Data was analyzed by the Content Analysis method. We conclude that educational institutions tend to reproduce the AM training model in the PM and the expectation of making the health service matter and reason for training is not sufficient to distinguish both modes. Key words Public health education, Professional training, Graduate studies, Master's program, Comparative studies
\end{abstract}

Resumo Ao buscar uma especificidade para o Mestrado Profissional (MP) em Saúde Pública, interrogamos, o que ele, ao se instituir, procurou do ponto de vista de seus meios e finalidades, conservar ou romper com os modelos de formação dos Mestrados Acadêmicos (MA). No campo da Saúde Pública, o tema ganha outros temperos se considerarmos que tanto o MP quanto o MA preservam na finalidade a formação para o Sistema Único de Saúde. Nesse sentido, a pesquisa buscou investigar a vocação heurística e inovadora do MP face ao MA como uma política pública de formação. Em uma perspectiva comparada, analisamos as principais características dos cursos de MP em saúde pública, frente ao processo de flexibilização da pós-graduação brasileira que o diferencia do MA, e discutimos se essas características tornam o MP uma política pública de formação. Na análise dos dados utilizamos o método da Análise de Conteúdo. Concluímos que as instituições de ensino tendem a reproduzir o modelo de formação do MA no MP e a expectativa de tornar o serviço de saúde matéria e motivo para a formação não é suficiente para distinguir ambas modalidades.

Palavras-chave Educação em saúde pública, Formação profissional, Educação de pós-graduação, Mestrado, Comparação 


\section{Introdução}

Ao buscar uma especificidade para o Mestrado Profissional (MP) em Saúde Pública, interrogamos, o que ele, ao se instituir, procurou do ponto de vista de seus meios e finalidades, conservar ou romper com os modelos de formação dos Mestrados Acadêmicos (MA). Se a questão nos interessa é porque o MP não somente preserva ambiguidades face ao MA, algo que consideramos uma questão persistente, mas também porque buscamos com a investigação realizada oferecer pistas que possam contribuir com a organização de cursos em ambas modalidades, de maneira a potencializar a formação stricto sensu.

No campo da Saúde Pública, o tema ganha outros temperos por considerá-lo parte do que chamamos de uma política pública de formação, posto que o MP vem se consolidando como uma alternativa na formação de profissionais para instituir novos processos de trabalho, produzir tecnologia e inovação para os serviços de saúde. Contudo, dizer que o MP está voltado para o serviço ao passo que o MA está voltado para o ensino e a pesquisa, como preconizam a legislação e os discursos mais comuns sobre o tema, torna-se algo desprovido de sentido, na medida em que uma e outra modalidades, acadêmica e profissional, preservam no horizonte de sua finalidade a formação para o Sistema Único de Saúde.

Com a pretensão de examinar o quão afirmativas são essas ideias, desenvolvemos uma pesquisa entre os anos de 2014 e 2016, a qual objetivou analisar, numa perspectiva comparada, as principais características dos cursos de MA e MP em saúde pública, frente ao processo de flexibilização da pós-graduação brasileira, e discutir se essas características diferenciam o MP como uma política pública de formação. Partindo, então, da premissa de que o MP tem um compromisso com a prática, perguntamos: ele cumpre sua vocação heurística e inovadora de formar para os serviços de saúde e, portanto, constituir-se-ia em uma política de formação? Sendo positiva a resposta, de que maneira se organiza e quais elementos da formação são considerados pelas instituições na implementação dessa política?

Sem a pretensão de esgotar essas questões, discutiremos aqui em que medida os cursos de MP e MA se organizam para cumprir as funções que socialmente lhes foram atribuídas, tomando como referência a finalidade do curso e os produtos finais apresentados pelos egressos. A escolha por analisar as finalidades decorrem do fato de entender que estão nelas as raízes que podem di- ferenciar o MP do MA. Quanto aos produtos, por considerá-los o resultado mais objetivo de uma proposta de formação com vistas a mudanças nos serviços de saúde.

\section{Método}

Inicialmente, identificamos 23 documentos oficiais sobre o MA e o MP e realizamos a análise dos registros escritos dessa legislação. Adotamos o mesmo procedimento com as propostas de cursos de MA e MP em atividade no período de 2002 a 2012, submetidos a, pelo menos, duas avaliações da Capes. Dos 77 Programas de Saúde Coletiva credenciados pela Capes, no período, pertencentes a 45 Instituições de Ensino Superior, selecionamos 27 propostas de cursos de MA e 11 de MP. Nessa etapa, utilizamos os seguintes critérios de inclusão: (1) cursos de MA e MP em funcionamento no período de 2002 a 2012, embora as propostas de curso tenham passado a ficar disponíveis no sítio da Capes a partir de 2004; (2) cursos selecionados terem sido submetidos a, pelo menos, duas avaliações da Capes. Pressupomos que a avaliação poderia oferecer às IES elementos para a reestruturação dos cursos, o que nos interessou, do ponto de vista do objeto desta pesquisa; (3) cursos que não foram descredenciados no período indicado, o que no escopo da pesquisa é um aspecto importante, posto que a continuidade de um curso de MP pode contribuir de maneira substancial para explicitar a identidade do MP face ao MA. E como critérios de exclusão: (1) cursos iniciados após 2008, pois não estariam dentro do critério de submissão a pelo menos duas avaliações; (2) cursos oferecidos em rede ou qualquer tipo de associação, porque obedecem a critérios de credenciamento específicos.

No levantamento dos trabalhos de conclusão dos cursos (TCC) selecionados identificamos 1078 de MA e 758 de MP. Dado o volume de TCC de MA, definimos uma amostra por conveniência, com os seguintes procedimentos: listamos cada TCC por IES, em ordem alfabética de autor, sorteamos em sequência um trabalho, excluindo o seguinte. A seleção final constou de 557 TCC de MA. Realizamos dez entrevistas com coordenadores dos cursos, cujos programas tivessem contemporaneamente MP e MA, aqui identificados pela letra E. A pesquisa foi aprovada pelo CEP-ENSP.

Para análise do corpus, utilizamos o método da Análise de Conteúdo ${ }^{1,2}$. Primeiro, realizamos a análise quantitativa dos dados para verificar a 
frequência de palavras ou temas predominantes no conjunto da legislação que tratava especificamente do MP e da pós-graduação stricto sensu, em separado, e do conjunto das sentenças gramaticais destacadas. Optamos pela escolha das 20 palavras (verbos e substantivos) mais frequentes no texto, as denominadas "palavras plenas".

Na sequência, fizemos a leitura flutuante de todos os textos da amostra com vistas a nos certificarmos da relação entre o seu conteúdo e os objetivos desse estudo; a segunda leitura foi para identificar frases, orações e ou períodos que estivessem relacionados às categorias previamente definidas: a) justificativa para o mestrado - diagnóstico que justificasse a existência do curso/ projeto de formação. Em muitos casos, não havia justificativa nos documentos analisados, o que nos levou a utilizar os objetivos geral e específicos das propostas; b) trabalhos de conclusão - tipo de produtos valorizados, objetivo geral dos trabalhos, métodos de pesquisa valorizados e recomendações feitas. Em uma terceira leitura, destacamos e agrupamos sentenças gramaticais identificadas de acordo com as categorias conforme o seu significado, além da identificação complementar de outras. Fizemos uma quarta leitura para nos certificarmos da interpretação dada nas leituras anteriores. As dúvidas foram discutidas coletivamente antes de se decidir pela classificação.

Das frases ou períodos selecionados, destacamos palavras plenas, verbos, substantivos, ocasionalmente adjetivos e advérbios; as expressões ou frases curtas (às vezes utilizamos o recurso da paráfrase, devidamente identificada pelo uso de parênteses). Reagrupamos esse conjunto em subcategorias de análise que foram organizadas em quadros, de acordo com os significados dos conteúdos. Após esse processo de categorização e codificação, procedemos à inferência dos dados. Nessa etapa de interpretação buscamos os significados expressos nas frases, sentenças e ou orações destacadas. Em grande parte desta etapa de pesquisa usamos um software de análise de dados qualitativos $^{3}$.

\section{Resultados e discussão}

Produto de uma criação datada da década de $90^{4}$, a legislação, antes de qualquer prática, procurou, ainda que preservando muitas ambiguidades ${ }^{5}$, estabelecer uma identidade para o MP, como veremos, ao mesmo tempo em que tratou de instituí-lo como a diferença na pós-graduação stricto sensu. E ao fazê-lo, como proposta alternativa de formação stricto sensu, criou um espaço, já abandonado, para se interrogar sobre as práticas e finalidades da formação de "pesquisadores". O surgimento da modalidade profissional não somente trouxe consigo a interrogação sobre a sua identidade, como também ao fazê-lo, colocou como exigência a necessidade de interrogar-se sobre a identidade do MA.

Desde a sua origem, a legislação estabeleceu como finalidade do MP uma "formação avançada e atualizada dos graduados", além da "transferência rápida de conhecimentos gerados pela universidade para sociedade" e maior aproximação das universidades com empresas, agências e governos $^{6}$. O texto da lei registra dois aspectos que orientarão o MP e que servem ao campo da Saúde Pública: a confirmação de um investimento na formação humana para uma fatia muito específica do mundo do trabalho - aquela que demanda por profissionais altamente qualificados; e o reconhecimento do isolamento da universidade, entenda-se mundo acadêmico, com o mundo produtivo, ao mesmo tempo, uma reivindicação para aproximar esses dois segmentos.

No que tange à formação de profissionais especializados para o setor produtivo, o MP objetiva algo que ficará mais explícito na Portaria $\mathrm{n}^{\mathrm{o}} 80$, de $1998^{7}$, a qual estabelece a finalidade da formação pelo MP: sujeitos "aptos a elaborar novas técnicas e processos” científicos, tecnológicos ou artísticos. Portaria no 7 , de $2009^{8}$, e por conseguinte, a Portaria $\mathrm{n}^{\circ} 17$, de $2009^{9}$, que a substituiu, cujo texto se mantém integral, é mais abrangente na definição da natureza específica da formação em nível de MP, pois promoveria a "formação de mestres profissionais habilitados para atividades técnico-científicos" e a "capacitação e treinamento de pesquisadores e profissionais (...) no processo produtivo de bens e serviços" com vistas a "atender áreas mais diretamente vinculadas ao mundo do trabalho e ao sistema produtivo". Isso se traduziria, portanto, na necessidade de estreitar a relação entre a academia e o profissional. Pela primeira vez, a legislação apontaria para uma estruturação própria do MP, com linhas de pesquisa voltadas para a produção de um tipo de conhecimento muito específico. E não somente isso, indicaria algo já previsto no Parecer $n^{\circ} 977$ de $1965^{10}$, incorporado como sendo também finalidade da pós-graduação: "identificar potencialidades para atuação local, regional, nacional e internacional" de modo a proporcionar o "desenvolvimento socioeconômico e cultural do País" por meio da especificidade de um tipo de 
"conhecimento científico e tecnológico a ser produzido e reproduzido".

$\mathrm{Na}$ Tabela 1 é apresentada a frequência de aparecimento das finalidades previstas nas propostas de cursos de MA e MP. Podemos observar que, nas propostas de MA, especificamente na sua justificativa, a finalidade dessa modalidade é a formação de pesquisadores, docentes e de profissionais do serviço. Embora as propostas utilizem outros termos como profissionais, recursos humanos, docentes, gestores, etc, adotamos os termos pesquisadores, professores e profissionais

Tabela 1. Frequência de aparecimento das finalidades formativa, científica e política dos Mestrados Acadêmico e Profissional descritos nas propostas de curso selecionadas.

\begin{tabular}{|c|c|c|c|c|c|}
\hline & & Mestrado Acadêmico & $\mathbf{n}^{\star}$ & Mestrado Profissional & $\mathbf{n}^{*}$ \\
\hline \multirow[t]{18}{*}{ Formativa } & Pesquisa & Pesquisadores & 14 & - & - \\
\hline & & Profissionais & 6 & - & - \\
\hline & & Recursos Humanos & 4 & - & - \\
\hline & & Científica / Acadêmica & 4 & - & - \\
\hline & & Pessoal capacitado & 1 & - & - \\
\hline & & $\begin{array}{l}\text { Básica nos temas da } \\
\text { Saúde Coletiva }\end{array}$ & 1 & - & \\
\hline & & Teórica & 1 & & - \\
\hline & Docência & Docente & 18 & $\begin{array}{l}\text { Cursos de graduação e } \\
\text { pós-graduação }\end{array}$ & 2 \\
\hline & & Profissionais & 7 & Docência & 2 \\
\hline & & Recursos Humanos & 5 & & - \\
\hline & & Acadêmica & 2 & & - \\
\hline & & Pessoal capacitado & 1 & & - \\
\hline & Serviço & Profissionais & 12 & Profissionais & 16 \\
\hline & & Recursos Humanos & 5 & Recursos Humanos & 14 \\
\hline & & Gestores & 2 & $\begin{array}{l}\text { Quadros técnicos e } \\
\text { gestores }\end{array}$ & 6 \\
\hline & & Pessoal & 1 & Pessoal & 3 \\
\hline & & & & Pesquisadores & 2 \\
\hline & & & & Ações de Saúde & 2 \\
\hline
\end{tabular}

\begin{tabular}{|c|c|c|c|c|}
\hline \multirow[t]{4}{*}{ Científica } & \multicolumn{4}{|l|}{$\begin{array}{l}\text { Contribuir / } \\
\text { Desenvolver }\end{array}$} \\
\hline & $\begin{array}{l}\text { Produção do } \\
\text { conhecimento }\end{array}$ & 9 & $\begin{array}{l}\text { Conhecimentos } \\
\text { e tecnologia }\end{array}$ & 3 \\
\hline & $\begin{array}{l}\text { Reflexões } \\
\text { interdisciplinares }\end{array}$ & 3 & $\begin{array}{l}\text { Pesquisa } \\
\text { científica na área }\end{array}$ & 2 \\
\hline & $\begin{array}{l}\text { Melhoria do ensino e } \\
\text { da pesquisa }\end{array}$ & 1 & & \\
\hline \multirow[t]{3}{*}{ Política } & $\begin{array}{l}\text { Com o Sistema Único } \\
\text { de Saúde }\end{array}$ & 3 & & \multirow{3}{*}{ Ver Tabela 2} \\
\hline & $\begin{array}{l}\text { Melhoria da saúde da } \\
\text { criança e da mulher }\end{array}$ & 1 & & \\
\hline & $\begin{array}{l}\text { Mudança na situação } \\
\text { de saúde da população }\end{array}$ & 1 & & \\
\hline
\end{tabular}

${ }^{\star}$ Frequência em que a justificativa aparece nos textos. 
do serviço como termos genéricos por acreditar que eles abrangem todos os demais descritos nas propostas; e reconhecer que eles se apoiam em diferentes tradições teóricas que não serão analisadas aqui, porque fogem ao escopo do estudo.

Já a produção científica e o fortalecimento das políticas de saúde ocupam uma dimensão secundária nas finalidades do curso pela frequência com que são referidos, o que não significa ser mesmo importante. Como exemplo temos: "contribuir para o desenvolvimento científico e tecnológico em Saúde Coletiva (...)"; "desenvolver estudos, métodos e técnicas para subsidiar [as políticas de saúde no Brasil]". Decerto que o ensino e a produção do conhecimento, no limite, voltam-se para o fortalecimento das políticas de saúde na medida em que visam ao fortalecimento do sistema de saúde, além de tomar os serviços como referência para as práticas de formação e de produção de conhecimento. Entretanto, na forma como aqui organizamos os dados, o fortalecimento das políticas de saúde ficou evidente como uma finalidade dos programas de mestrado acadêmico intencionalmente explicitada em suas propostas.

Em síntese, predomina no MA a perspectiva de formar pesquisadores e docentes, pois é referida, respectivamente 31 e 33 vezes, ao passo que a formação de profissionais para o serviço é referida 20 vezes. Já a produção de conhecimento científico está presente nas propostas de duas maneiras: uma que visa contribuir com a produção e melhoria do conhecimento, nove vezes, e outra que busca desenvolver reflexões e conhecimentos científicos e tecnológicos, três vezes. A finalidade de fortalecimento das políticas de saúde é recorrente nos textos das propostas de curso e, na maioria das vezes, identificada pela expressão “formar para o SUS". Algumas propostas explicitaram a perspectiva de contribuir com o sistema de saúde (5 vezes), ou desenvolver ensino e pesquisa integrado à cooperação técnica (2 vezes).

Obviamente, tanto a perspectiva da formação quanto a produção científica teriam como finalidade o fortalecimento das políticas de saúde, porque, de maneira geral, o campo de estudo dos pesquisadores da área é a própria saúde pública, como explicitado em uma das propostas: "formação de profissionais qualificados para o exercício de atividades em ensino, pesquisa e em gestão de serviços direcionados à Saúde Coletiva”. Da mesma maneira, esses pesquisadores formados atuarão, na grande maioria, como docentes de universidades ou escolas de saúde que contribuem, direta ou indiretamente, para formação de novos profissionais no campo.
Diferentemente, no entanto, embora com algumas semelhanças, é a finalidade do MP na dimensão política, cuja ênfase é a formação para o serviço, mediante a formação de quadro profissionais. No que pese o fato da pós-graduação em Saúde Pública esteja, conforme as propostas, comprometida com a formulação e implementação da política de saúde do país, nas propostas de MP, esse aspecto é mais explícito. Há propostas de curso que sinalizaram para uma dimensão estratégica, visando ao fortalecimento do próprio programa de formação; outras, de maneira curiosa, sinalizaram, como perspectiva do MP, a produção de conhecimento e a formação para a docência. A curiosidade reside no fato das propostas não enfatizarem a produção de conhecimento e de tecnologia como uma de suas finalidades, a exceção de cinco delas que destacam a produção de tecnologia e a produção científica na área do MP. Outra curiosidade está no fato de duas propostas fazerem referência à formação de docentes, mesmo quando a legislação, por algumas vezes, explicita não ser esta a finalidade do MP, exceto aqueles cursos destinadas à Educação Básica.

$\mathrm{Na}$ perspectiva da formação para o serviço, tanto o MP quanto o MA se assemelham, exceto pelo fato da frequência nos objetivos das propostas de MP que estabelece como finalidade da formação os serviços de saúde ser bem maior no MP, em número de 43. Embora apareça duas vezes "capacitação de pesquisadores" nas finalidades das propostas, elas fazem menção à formação de profissionais do serviço que farão uso da pesquisa científica em suas atividades. Esses profissionais, de maneira semelhante às propostas pelo MA, são denominados de recursos humanos, profissionais, quadros estratégicos, pessoal, gestores. Dois aspectos chamam a atenção na maneira de descrever os profissionais do serviço e que se distinguem do modo como as propostas de MP o fizeram: um é a denominação "quadros estratégicos" (6 vezes), porque pressupõe um tipo de formação que é institucional e não individual; outra peculiaridade é o registro dos vocábulos "necessidade" e "demanda" que, nesse contexto, pode significar cursos que foram oferecidos sob encomenda. No que refere-se à produção de conhecimento, desenvolvimento de tecnologias e de pesquisa científicas, esses termos apareceram 4 vezes.

O que também fica evidente em relação à finalidade política nas propostas de MP (Tabela 2), é a de contribuir para a melhoria da gestão do sistema de saúde, seja no que diz respeito ao 
"fortalecimento da liderança e da tomada de decisão", seja na melhoria da qualidade do serviço por meio de planejamento e gestão de qualidade, ou ainda, na "formulação de políticas de saúde e consolidação do Sistema de Saúde". Essa finalidade apareceu 28 vezes nas propostas. Observamos também um claro interesse pela avaliação dos serviços de saúde, no que diz respeito ao uso de novas tecnologias ou instrumentos em determinada situação de trabalho, com a finalidade de instituir processos de mudança e diagnosticar efeitos de determinadas intervenções realizadas nos serviços. A avaliação, além de fazer parte da "dimensão política" da formação, também objetiva o "acompanhamento" e "monitoramento" de práticas dos serviços de saúde, buscando compreender a relação custo-efetividade, além de pretender a "organização dos serviços" e a instituição de "protocolos baseados em evidência científica”.

Outro aspecto da perspectiva de formar para o sistema de saúde é a possibilidade de inovação tecnológica e de uso da investigação científica para melhorar a qualidade dos serviços, com o desenvolvimento de "atividades de pesquisa" e a "utilização da investigação científica". Esse processo é considerado estratégico enquanto potencialidade de disseminação dos conhecimentos científicos e, também, a produção de conheci- mento e inovação no local de trabalho (11 vezes). Por fim, o desenvolvimento de redes de informações como forma de promover intercâmbios e a divulgação de conhecimentos e troca de experiências, com vistas ao fortalecimento do sistema de saúde, também é uma das finalidades apontadas pelas propostas de cursos de MP (10 vezes).

Os entrevistados, por sua vez, confirmam que a diferença entre o MP e o MA parece residir na finalidade de uma e outra modalidades. O MP voltado para o serviço é, segundo a fala dos coordenadores, o que pode distinguir o MP do MA e justificar, inclusive, a existência daquele:

O MP não é aberto para livre demanda, ele é aberto para as pessoas que estão inseridas no serviço de saúde. (E10);

[...] o MP é para responder a uma demanda do Ministério. (E7)

[...] o MP visa a formação de pessoal para o SUS (...) (E5)

[...] o MP (...) é voltado ao serviço. O MA [...] é uma formação que [...] tem como objetivo maior essa primeira formação cientifica, é o inicio do pesquisador." (E3)

[O MP] é para instrumentalizar para o serviço, qualificar o serviço, para melhorar a qualidade de atendimento ao usuário. [...] Ao passo que o MA [...] é para formar pesquisadores (E2).

Tabela 2. Frequência de aparecimento da finalidade política das Propostas de Cursos selecionados do Mestrado Profissional.

\begin{tabular}{|c|c|c|c|}
\hline Gestão & $\mathbf{n}^{*}$ & Desenvolvimento de redes de informações & $\mathbf{n}^{*}$ \\
\hline Melhoria da qualidade dos serviços & 7 & Divulgação do conhecimento (...) & 4 \\
\hline Desenvolvimento da gestão & 7 & Conhecimentos e experiências (...) & 1 \\
\hline Desempenho das funções de gestão & 6 & Às ações de gestão de tecnologias & 1 \\
\hline Formulação e implementação de políticas & 2 & Construção de um polo regional & 1 \\
\hline Incorporação do enfoque epidemiológico & 3 & Ampliar o escopo de titulação do Programa & 1 \\
\hline Elevação da qualidade de vida & 2 & $\begin{array}{l}\text { Consolidar o lugar de referência/excelência } \\
\text { da instituição no campo. }\end{array}$ & 1 \\
\hline Resolubilidade dos cuidados básicos; & 1 & $\begin{array}{l}\text { Estabelecer uma relação mais estreita entre a } \\
\text { Pós-Graduação stricto e lato sensu }\end{array}$ & 1 \\
\hline Avaliação & & Pesquisa/inovação & \\
\hline Organização de serviços e avaliação & 2 & Atividades de pesquisa & 7 \\
\hline Gestão de tecnologias em saúde; & 2 & Utilização da investigação científica & 4 \\
\hline Técnicas e instrumentos & 2 & & \\
\hline Processos de mudança & 2 & & \\
\hline Análise ou diagnóstico de situações de saúde & 1 & & \\
\hline Intervenções implantadas pelos serviços; & 1 & & \\
\hline Utilização de indicadores de saúde & 1 & & \\
\hline Implementação, monitoramento e avaliação; & 1 & & \\
\hline Protocolos baseados em evidências & 1 & & \\
\hline
\end{tabular}

${ }^{\star}$ Frequência em que a justificativa aparece nos textos. Fonte: CAPES. 
Dessa perspectiva, ainda tomando como base o escopo da legislação e das entrevistas, podemos inferir que, do ponto de vista da finalidade, a tendência mais evidente que diferencia o MA e o MP é que o primeiro visa à formação de docentes e pesquisadores, ao passo que o segundo, visa à gestão dos serviços de saúde, à avaliação e ao desenvolvimento de tecnologias.

Nada seria mais tentador, porém, aceitar essa resposta tão evidente que dispensaria qualquer reflexão teórica ou empírica, se essa primeira impressão não tivesse que ser submetida ao crivo da crítica. Primeiro, essas palavras representam um conjunto de intenções que, a despeito do poder que o texto escrito pode exercer sobre as nossas intencionalidades e ações, como lembra Hannah Arendt ${ }^{11}$ nos inserimos no mundo humano por meio de atos e palavras, a distância entre o dito e o feito jamais pode ser desconsiderada; segundo, estamos em um terreno cuja legislação ainda é a principal referência que serve de modelo para as práticas sociais de formação nessa modalidade. Mas essa tendência do texto das propostas reproduzirem o que diz a legislação não é somente porque veem nelas uma referência para orientar as práticas de formação mas, principalmente, porque as propostas são julgadas segundo critérios estabelecidos por essas mesmas leis. Por fim, a definição apresentada é a mais evidente e em nada acrescenta à reflexão sobre a identidade do MP. A simplicidade da resposta, entretanto, não engana, posto que diz respeito ao aspecto que orienta todos os demais: falamos da finalidade dos cursos de MP e MA que ratifica, ao menos no plano do discurso, o que uma e outra modalidade podem apresentar sobre o que tem de comum e próprio que, nesse caso, ainda permanece ambíguo.

Desde a sua origem, o MP buscou uma finalidade que o MA não alcançava - formar quadros profissionais estratégicos. No caso da Saúde Coletiva, essa razão não pareceu necessária e suficiente posto que a formação é visada pela genérica expressão "formar para o SUS", como mostram as propostas dos cursos. Isto somente reforça nossa hipótese sobre a identidade destas modalidades que, em vários momentos se aproximam e convergem para uma mesma finalidade. Contudo, apresentam diferenças significativas. As propostas de cursos de mestrado objetivam formar para pesquisa, docência e serviço, ao passo que as de MP, o maior interesse é formar para o serviço, ainda que a formação para a docência apareça menos frequentemente.

Do ponto de vista da dimensão científica, em seu aspecto intencional trata-se, evidente- mente, de um elemento expressivo nas proposta de MA que desaparece ou fica subsumido nas demais dimensões (formação para o serviço ou fortalecimento das políticas de saúde), quando nos referimos ao MP. Por outro lado, quando se trata da dimensão política de fortalecimento do sistema de saúde, a situação se inverte, na medida em que o tema é referenciado de maneira explícita nas propostas de MP; nas propostas de MA ele é mencionado de forma genérica ou simplesmente omitido. Notamos que a finalidade do MP em Saúde Pública é atender a uma demanda especifica de formação de quadros estratégicos, ao passo que o MA se volta para a formação de pesquisadores. Em resumo, um destina-se à formação para o serviço enquanto o outro à formação científica. Nesse sentido, o MP se apresenta como uma possibilidade de se constituir como política pública de formação, na medida em que serve para atender a interesses públicos ou setorizados, do governo ou de sociedade, na formação de quadros profissionais estratégicos. Evidentemente, a expectativa em formar técnicos para o serviço de saúde significa não somente que o egresso seja melhor qualificado, mas que o próprio serviço seja matéria e motivo do processo de formação. Diferentemente, portanto, do papel do MA, que é o de acolher alunos sem essa experiência e que desejam seguir carreira acadêmica. Em outras palavras, se essas finalidades buscam se estabelecer como distintas, pressupõe financiamento e TCC conformes à finalidade de uma e outra modalidades de mestrado.

Para se constituir como política pública de formação, o MP em Saúde Pública assume uma forma especifica de financiamento. As referências à concessão de bolsas, por exemplo, somente aparecem na legislação, na Portaria $\mathrm{n}^{\circ} 7$, no art. 11 que diz: "salvo em áreas excepcionalmente priorizadas, o mestrado profissional não pressupõe, a qualquer título, a concessão de bolsas de estudos pela Capes". Esta ressalva se deve ao fato de a Capes "vir a apoiar, no todo ou em parte, iniciativas particularmente voltadas para o desempenho de funções básicas do Estado", como destacado no artigo c, dos Parâmetros de Avaliação ${ }^{12}$ e se comprometer por exemplo, com a formação de professores da educação básica, passando a oferecer bolsas de estudos a estes profissionais que desejam fazer MP, na modalidade EAD. A Portaria $\mathrm{n}^{\circ}$ 478 , de 29 de abril de $2011^{13}$ altera a Portaria $n^{\circ}$ 289 , de 21 de março de $2011^{14}$, que dispõe sobre a concessão de bolsas de formação para professores da rede pública matriculados em cursos de Mestrado Profissional. Passa a vigorar a seguinte 
redação: “(...) Criar a Bolsa de Formação Continuada destinada a professores da Rede Pública da Educação Básica, regularmente matriculados em cursos de Mestrado Profissional ofertados pelas instituições de ensino superior, devidamente aprovados pela CAPES (...). A concessão da Bolsa de Formação Continuada tem como abrangência os alunos matriculados a partir de 2011 nos cursos de mestrado profissional em funcionamento no país"

Segundo a Portaria no 80, de 1998, "os cursos da modalidade possuem vocação para o autofinanciamento". Apesar desta portaria ter sido revogada pela de $\mathrm{n}^{\circ} 7$ de 2009 e, posteriormente, pela de $\mathrm{n}^{\circ} 17$ de 2009 , o espírito da lei, que vigora desde a implementação do Programa de Flexibilização da Pós-Graduação, permaneceu inalterado. Cabe, portanto, às IES que oferecem MP demonstrar que têm as condições materiais necessárias para viabilizar o curso.

O texto da lei, ao mencionar as instituições demandantes, refere-se aos órgãos públicos diversos, às empresas privadas e às organizações não governamentais, etc. Nesse caso, respeitando as regras gerais inerentes a qualquer pós-graduação stricto sensu, o MP é um curso que visa, ao menos no campo da saúde pública, a um novo modelo de formação que atenderia às necessidades dos serviços de saúde. Esse dado é corroborado pela fala dos entrevistados.

[...] geralmente é o Ministério da Saúde ou Secretarias de Saúde, municipal ou estadual, que encomendam (E6).

[...] necessidade do Sistema de Saúde brasileiro estar mais pautado em evidências, em diretrizes clínicas, em protocolos clínicos (E9).

[...] o Ministério da Saúde financia o MP, mas financia para determinado perfil (E3).

[...] a gente tem oferecido turmas ao Ministério da Saúde, a Secretarias Estaduais de Saúde [...] (E5).

No caso do MP em Saúde Pública, a demanda é basicamente do Ministério e Secretarias de Saúde, estaduais e municipais. Esses órgãos podem ver no MP uma possibilidade de implementar políticas de saúde, por meio da qualificação dos seus quadros profissionais e também apostam em um nível de formação (stricto sensu) de alto padrão.

Desde sua origem, o MP tem "vocação" para o autofinanciamento, diferentemente do MA que é financiado pelo Ministério da Educação e pelo Ministério de Ciência e Tecnologia, por meio de suas agências de fomento. E a legislação pouco se preocupou em definir melhor essa matéria, a não ser para anunciar claramente seu desinteresse em sustentar cursos dessa modalidade. Tratando-se da Saúde Pública, isto não significa ausência de financiamento público para o MP; os cursos de MP das instituições públicas e privadas de ensino são financiados pelo Ministério e Secretarias de Saúde, sem contar com a contrapartida das IES no que diz respeito aos docentes, infraestrutura, além de todos os demais recursos necessários ao seu funcionamento, que acabam por servir aos cursos de MP, um custo provavelmente não contabilizado nos orçamentos das propostas. Muitas vezes essa política de formação caracteriza-se como uma demanda do serviço; contudo não identificamos, dentre as fontes investigadas, dados que justifiquem essa escolha. Apesar disso, o financiamento estatal indica o interesse, no campo da Saúde Pública, em tornar o MP uma política pública de formação.

Quando nos voltamos para análise dos trabalho finais de MP e MA, a distinção entre eles ainda é pouco evidente. A Tabela 3 apresenta o percentual dos três formatos mais frequentes: dissertação, artigo e projeto de pesquisa com artigo. Tanto no MA quanto no MP, o maior percentual foi o formato de dissertação, ou seja, 72,35\% para os MA e $88,52 \%$ para os MP, o que indicaria forte influência dos modelos acadêmicos de formação no MP. Quanto às recomendações, em torno de $47 \%$ dos TCC não fizeram qualquer recomendação e nem a explicitaram, ao menos nos resumos e nas conclusões. Para o MA, embora não esteja previsto, 11 produtos apresentaram recomendações.

Em relação à metodologia dos estudos, devido à grande variedade de formas de explicitá-la, consideramos o que foi descrito no TCC e padronizamos cinco tipos de estudo, a partir de Ann Bowling ${ }^{15}$ : estudos epidemiológicos que compõem os estudos de casos prospectivos e retrospectivos, inquéritos (amostras para uma doença ou população especifica), estudos ecológicos (exposição ao risco de grupo populacional), estudos casocontrole (prospectivos ou retrospectivos), pesquisa documental (banco de dados estatísticos), estudos de coorte longitudinais e prospectivos, estudos randomizados; estudos experimentais (humanos e animais); estudos econômicos que são analise de custo-efetividade, análise de custo-benefício, análise de custo-utilidade; estudos qualitativos observacionais (observação participante, triangulação de métodos, observação estruturada e não-estruturada - grupo focal, narrativas, conversação (uso de técnicas de escuta); e estudos com uso de técnicas quanti e quali abrangendo es- 
tudo de caso, consenso (Delphi, grupo nominal), pesquisa-ação e técnicas de avaliação rápida, pesquisa documental.

Podemos observar na Tabela 4 que predominam em ambas modalidades os estudos epidemiológicos. Essa abordagem, somada às outras quatro abordagens metodológicas mais frequentes, representaram mais $92 \%$ das abordagens metodológicas entre os TCC de MA. Embora com pequena variação em relação ao $\mathrm{MA}$, as outras quatro abordagens metodológicas mais frequentes no MP também representaram mais de 92\% das abordagens metodológicas dos TCC. Os estudos de caso e qualitativos, e as pesquisas documentais estão presentes em ambas modalidades, com variações quanto à frequência. A realização de pesquisas experimentais seria a diferença substancial entre as dissertação de MA e os estudos avaliativos no MP.

Os verbos mais frequentes nos objetivos dos TCC dos mestrados são apresentados na Tabela 5. Os dez verbos mais frequentes nos trabalhos de MA correspondem a 91\% do total de verbos; e os dez mais frequentes nos trabalhos de MP representam 55\% do total dos verbos. Interessante observar que os três objetivos mais frequentes são os mesmos para ambas as modalidades. Chama a atenção que quase $45 \%$ dos verbos utilizados nos trabalhos de MP estejam registrados em "outros", o que poderia significar uma maior variedade de possibilidades de pesquisa nesta modalidade.

Podemos concluir que os TCC de ambas modalidades são muito semelhantes, não apenas quanto ao formato e tipo de estudos realizados, mas também no que se refere aos objetivos desses estudos. A razão mais evidente seria a tendência do MP reproduzir os esquemas já consolidados no MA, e a dissertação e artigo serem produtos canônicos de pesquisa no ambiente acadêmico. Outra possibilidade, intrinsecamente relaciona-

Tabela 3. Distribuição percentual dos tipos de produtos finais nos cursos selecionados de Mestrados Acadêmico e Profissional.

\begin{tabular}{lrrrr}
\hline \multirow{2}{*}{ Tipo de produto } & \multicolumn{2}{c}{ MA } & \multicolumn{2}{c}{ MP } \\
\cline { 2 - 5 } & $\mathbf{n}$ & \multicolumn{1}{c}{$\%$} & \multicolumn{1}{c}{ n } & \multicolumn{1}{c}{$\%$} \\
\hline Dissertação & 403 & 72,35 & 671 & 88,52 \\
Formato de artigo & 154 & 27,64 & 47 & 6,21 \\
$\begin{array}{l}\text { Formato de projeto de } \\
\text { pesquisa com artigo }\end{array}$ & - & - & 35 & 4,62 \\
Outros & - & - & & \\
Total & 557 & 100 & 758 & 100 \\
\hline Fonte: dados da pesquisa & & & &
\end{tabular}

da, seria a maneira como os docentes tradicionalmente operam na orientação desses produtos e, por ignorarem outros formatos ou não os reconhecerem como legítimos, optariam por reproduzir o modelo academicamente consolidado. Pelo mesmo lado, a produção acadêmica de artigos tem sido um critério bastante valorizado na avaliação dos programas de pós-graduação no Brasil, o que leva docentes e alunos a optarem por formatos que facilmente são convertidos em publicações em revistas indexadas.

Tabela 4. Distribuição percentual de abordagens metodológicas nos produtos finais dos cursos selecionados de Mestrados Acadêmico e Profissional.

\begin{tabular}{|c|c|c|c|c|c|}
\hline $\begin{array}{c}\text { Mestrado } \\
\text { Acadêmico }\end{array}$ & $\mathbf{n}$ & $\%$ & $\begin{array}{c}\text { Mestrado } \\
\text { Profissional }\end{array}$ & $\mathbf{n}$ & $\%$ \\
\hline $\begin{array}{l}\text { Estudo } \\
\text { epidemiológico }\end{array}$ & 226 & 40,57 & $\begin{array}{l}\text { Estudo } \\
\text { epidemiológico }\end{array}$ & 174 & 22,96 \\
\hline Estudo de caso & 88 & 15,80 & $\begin{array}{l}\text { Estudo } \\
\text { qualitativo }\end{array}$ & 144 & 18,99 \\
\hline $\begin{array}{l}\text { Estudo } \\
\text { qualitativo }\end{array}$ & 78 & 14,00 & $\begin{array}{l}\text { Pesquisa } \\
\text { avaliativa }\end{array}$ & 140 & 18,47 \\
\hline $\begin{array}{l}\text { Pesquisa } \\
\text { documental }\end{array}$ & 73 & 13,11 & Estudo de caso & 130 & 17,15 \\
\hline $\begin{array}{l}\text { Estudo } \\
\text { experimental }\end{array}$ & 49 & 8,80 & $\begin{array}{l}\text { Pesquisa } \\
\text { documental }\end{array}$ & 120 & 15,83 \\
\hline $\begin{array}{l}\text { Outras } \\
\text { abordagens }\end{array}$ & 43 & 7,72 & $\begin{array}{l}\text { Outras } \\
\text { abordagens }\end{array}$ & 50 & 6,60 \\
\hline Total & 557 & 100 & Total & 758 & 100 \\
\hline
\end{tabular}

Tabela 5. Distribuição percentual dos verbos nos objetivos dos Trabalhos de Conclusão de Curso dos cursos selecionados de Mestrados Acadêmico e Profissional.

\begin{tabular}{lrrlrr}
\hline \multicolumn{1}{c}{$\begin{array}{c}\text { Mestrado } \\
\text { Acadêmico }\end{array}$} & $\mathbf{n}$ & $\%$ & $\begin{array}{c}\text { Mestrado } \\
\text { Profissional }\end{array}$ & $\mathbf{n}$ & $\%$ \\
\hline Analisar & 193 & 34,65 & Analisar & 127 & 16,75 \\
Avaliar & 113 & 20,29 & Avaliar & 105 & 13,85 \\
Descrever & 54 & 9,69 & Descrever & 41 & 5,41 \\
Compreender & 38 & 6,82 & Identificar & 25 & 3,30 \\
Investigar & 24 & 4,31 & Conhecer & 25 & 3,30 \\
Identificar & 22 & 3,95 & Investigar & 24 & 3,17 \\
Estudar & 18 & 3,23 & Caracterizar & 21 & 2,77 \\
Determinar & 18 & 3,23 & Realizar & 20 & 2,64 \\
Conhecer & 15 & 2,69 & Elaborar & 16 & 2,11 \\
Estimar & 14 & 2,51 & Verificar & 13 & 1,72 \\
Outros & 48 & 8,62 & Outros & 341 & 44,99 \\
Total & 557 & 100 & Total & 758 & 100 \\
\hline Fonte: dados da pesquisa & & & &
\end{tabular}


Ora, mesmo com semelhanças tão evidentes, em que medida os produtos dos MP espelham aquilo que é necessidade para os serviços de saúde? A resposta à questão nos leva até à especificidade do MP, explicitado pela legislação desde 1995, que é a aproximação da academia com o mundo do trabalho. No caso da Saúde Pública, isso se traduziria, em outras palavras, além da formação de profissionais para o serviço de saúde, na produção de conhecimento e de tecnologia de interesse para esse serviço. Trata-se de um aspecto pelo qual a academia, não raro, é objeto de críticas, a de fechar-se para questões que realmente interessam ao mundo do trabalho. Obviamente, essa afirmativa não é inteiramente verdadeira e nem aplicada a todas as áreas do conhecimento; afinal, em que se baseiam as pesquisas acadêmicas no campo da saúde pública senão de problemas e questões oriundos dos serviços? Além disso, não é de hoje que muitas pesquisas realizadas nas universidades são financiadas por empresas que buscam uma solução para um produto ou serviço, ou mesmo uma nova tecnologia, o que espelha outra forma de aproximação.

O MP, portanto, criou a possibilidade de maior abertura da academia para o setor de serviços, setor produtivo, mercado de trabalho; ao mesmo tempo, essa abertura colocou como exigência para as IES uma nova maneira de organizar a formação e a pesquisa na pós-graduação brasileira. Isto porque passou a exigir dessas instituições não somente o reconhecimento das necessidades do mundo do trabalho como também uma reorganização no sentido de corresponder àquilo que delas estava sendo demandado, algo que a pós-graduação stricto sensu jamais ousou fazer.

Essa significação da qual está investida o MP, a formação de profissionais que fazem uso da ciência para melhor qualificar o seu trabalho, não parece distinguir-se do MA, ao contrário, é exatamente o ponto em comum entre uma e outra modalidades. Essa pedagogia pela pesquisa é, segundo Bourdieu ${ }^{16}$, uma espécie de modus operandi, atividade cuja prática, firmada no contrato pedagógico entre aquele que ensina e aprende, para além da transmissão dos saberes que fazem do aprendiz um mestre no domínio da arte de fazer ciência

...porque não há outra maneira de adquirir os princípios fundamentais de uma prática - e a prática científica não é exceção - que não seja a de praticar ao lado de uma espécie de guia ou treinador, que protege e incute a confiança, que dá o exemplo e que corrige ao enunciar, em situação, os preceitos diretamente aliados ao caso particular [grifos do autor].

Encontramos nesse autor pistas para uma organização curricular capaz de fazer da prática de pesquisa matéria e motivo para formação. Contudo, esse princípio não aparece de maneira evidente na formação do mestre acadêmico ou profissional e, desse ponto de vista, o segundo tende a ser um reflexo do primeiro, exceto pelo fato de um público específico apresentar objetos de estudo decorrentes do próprio trabalho, uma evidência conservadora da academia para se aventurar em novas maneiras de organização e produção de conhecimento, ainda não consolidados na pós-graduação, ou ainda, da possibilidade do trabalho final dos egressos se reverterem em práticas para os serviços.

\section{Considerações Finais}

O modo pelo qual procuramos definir o MP consistiu em investigar suas características, aquelas que o fazem se diferenciar e, por outro lado, se aproximar do MA. Não tratou, portanto, de uma descrição pela negativa, enunciado por um conjunto finito de predicados que expressam aquilo que não é o $\mathrm{MP}$, a maneira mais trivial, porém empobrecida para toda definição. Menos ainda foi nossa tarefa identificar uma qualidade ou atributo próprio e essencial equivalente a uma substância, algo que julgamos improvável, pela natureza do nosso objeto de pesquisa.

A análise das finalidades das propostas mostra que não há distinção absoluta entre as características de ambas modalidades de mestrado. Tanto o MP quanto o MA formam profissionais para o sistema de saúde com variações de graus, posto que é notória a finalidade do MA na formação de docentes e de pesquisadores, enquanto no MP predomina a formação para o serviço. No que diz respeito aos TCC, o MA, por estar consolidado e com regras definidas, tende a ser mais homogêneo, ao passo que o MP tem características mais diversificadas, sem contudo apresentar formatos distintos daqueles já consolidados.

Nisso consiste a dimensão da formação como política pública. Primeiro, o financiamento é público, o que mostra um interesse na formação de profissionais que tenham melhor qualificação para exercer suas atividades. Segundo, o investimento no MP pressupõe o fortalecimento de uma política pública de saúde. E para que esse projeto se realize, há uma aposta na formação pela ciência, que seria capaz de possibilitar a 
construção das ferramentas necessárias à melhorar a qualidade dos serviços. É claro que a maneira como esse processo se dá e as condições de seu acontecimento, bem como a avaliação para verificar os resultados desse investimento, é algo que ainda precisa ser investigado.

Os dados confirmam o que dizem a legislação e as propostas de cursos, mas param por aí. A análise aqui empreendida nos permite concluir que a expectativa de tornar o serviço de saúde objeto para a formação não é suficiente se não vier acompanhada de evidências que justifiquem essa necessidade, e principalmente, sem um estudo que evidencie se todo investimento na formação resultou em mudanças significativas no ambiente de trabalho. Desse ponto de vista, não identificamos nenhum dado no corpus da pesquisa.

A legislação contribuiu, sem dúvida, para fortalecer a identidade do MP, ao mesmo tempo em que ofereceu elementos comuns e próprios desta modalidade de ensino face ao MA, no que diz respeito à prática de formação. Ao que parece, texto da Lei exerce influência sobre as práticas de formação das IES que oferecem cursos de pós-graduação; não que o mecanismo legal seja capaz de definir e, por conseguinte, esgotar as práticas de formação mas, nesse caso particular, a legislação é a principal fonte de referência para organizar o MP.
Por sua vez, a construção da identidade do MP depende da identidade do MA, ou seja, o MA precisa se reestruturar e assumir a identidade de formar para a academia (professores e pesquisadores) ao passo que a tarefa de formar para o serviço deve ser destinada ao MP. Nessa perspectiva, o MA visa a formação de indivíduos ao passo que o MP destina-se à formação de quadros estratégicos. Neste sentido, o primeiro sugere uma organização curricular em função das áreas de conhecimento e expertise da IES, enquanto o segundo, ainda que respeitada a expertise da IES, passa a ser organizado em função do perfil e necessidades do público a ser atendido. Por sua vez, os produtos "dissertação" (no sentido clássico do termo) e "artigos" no MP somente passam a ter sentido quando assumem o papel de descrever tecnologias, processos de trabalho, protótipos elaborados com vistas a um retorno mais objetivo ao serviço, o que daria ao TCC do MP maior complexidade em relação ao MA, exigindo portanto, um currículo organizado em função dessas necessidades e características. Especificamente no caso do $\mathrm{MP}$, essa organização serve tanto a um conjunto de atividades convergentes voltadas para o TCC que será ou não aplicado nas instituições, quanto parte da prática dos agentes como cenário para a construção de novos conhecimentos.

\section{Colaboradores}

GB Santos e VA Hortale trabalharam na concepção do estudo, na análise dos dados e na redação do artigo. KM Souza e APGF Vieira-Meyer participaram da coleta e análise dos dados e na redação do artigo. 


\section{Referências}

1. Holsti OR. Content Analysis for the social sciences and humanities. Boston: Addison-Wesley; 1969.

2. Bardin L. Análise de conteúdo. Lisboa: Edições 70; 1977.

3. NVivo qualitative data analysis Software. QSR International Pty Ltd. Version 10, 2014.

4. Santos GB, Hortale VA, Arouca R. Mestrado Profissional em Saúde Pública: caminhos e identidade. Rio de Janeiro: Fiocruz; 2012.

5. Santos GB, Hortale VA. Mestrado Profissional em Saúde Pública: do marco legal à experiência em uma instituição de pesquisa e ensino. Cien Saude Colet 2014; 19(7):2143-2155.

6. Coordenação de Aperfeiçoamento de Pessoal de Nível Superior (Capes). Programa de Flexibilização da Pósgraduação. Brasília: Capes; 1995.

7. Brasil. Portaria ${ }^{\circ}{ }^{80}$, de 16 de dezembro de 1998. Dispõe sobre o reconhecimento dos mestrados profissionais e dá outras providências. Diário Oficial da União 1999; 11 jan.

8. Brasil. Portaria Normativa $n^{\circ} 7$, de 22 de junho 2009. Dispõe sobre o mestrado profissional no âmbito da Fundação Coordenação de Aperfeiçoa- mento de Pessoal de Nível Superior. Diário Oficial da União 2009; 23 jun.

9. Brasil. Portaria Normativa $\mathrm{n}^{\circ} 17$, de 28 de dezembro 2009. Dispõe sobre o mestrado profissional no âmbito da Fundação Coordenação de Aperfeiçoamento de Pessoal de Nível Superior - Capes. Diário Oficial da União 2009; 29 dez.
10. Brasil. Parecer CFE no 977, de 3 de dezembro de 1965. Definição e regulamentação de cursos de pós-graduação.

11. Arendt H. A condição humana. Rio de Janeiro: Forense Universitária; 2002.

12. Capes. Parâmetros para avaliação de mestrado profissional. Documentos RBPG 2005; 2(4):151-155.

13. Capes. Portaria $n^{\circ} 478$, de 29 de abril de 2011. Dispõe sobre a concessão de bolsas de formação para professores da rede pública matriculados em cursos de Mestrado Profissional. Diário Oficial da União 2011; 2 maio.

14. Capes. Portaria no 289, de 21 de março de 2011. Dispõe sobre a concessão de bolsas de formação para professores da rede pública matriculados em cursos de Mestrado Profissional. Diário Oficial da União 2011; 22 mar.

15. Bowling A. Research methods in health: investigating health and health services. London: Open University Press; 1997.

16. Bourdieu P. O poder simbólico. Rio de Janeiro: Bertrand do Brasil; 2012.

Artigo apresentado em 14/11/2016

Aprovado em 21/03/2017

Versão final apresentada em 23/03/2017 